\title{
A questão da ideologia de gênero nas escolas brasileiras: o (des)compasso entre os fundamentos elencados na ADPF 457/GO e no Projeto de Lei 246/20191
}

\author{
The issue of gender ideology in brazilian schools: \\ the (dis)alignments between the foundations elected in the ADPF 457/GO and \\ in the Bill 246/2019
}

Mônia Clarissa Hennig Leal
Universidade de Santa Cruz do Sul - UNISC
Pós-doutora pela Ruprecht-KarlsUniversität Heidelberg (Alemanha)
Professora e Coordenadora do PPGD UNISC
Santa Cruz do Sul - RS - Brasil
moniah @ unisc.br
Eliziane Fardin de Vargas
Universidade de Santa Cruz do Sul - UNISC
Mestranda em Direito
Bolsista CAPES/PROSUC, modalidade II
Santa Cruz do Sul - RS - Brasil
elizianefvargas@ @ $x 2$. unisc.br

Resumo: Neste artigo pretende-se, através do método dedutivo, responder ao seguinte questionamento: há um (des)compasso entre o conteúdo do Projeto de Lei 246/2019 e os fundamentos utilizados pelo Supremo Tribunal Federal na decisão da ADPF 457/GO? Para isso analisar-se-á, num primeiro momento, a importância da abordagem sobre gênero e diversidade sexual no ambiente escolar para a proteção das minorias sexuais e de gênero, sob a respectiva do dever de proteção estatal (Schutzpflicht) decorrente da dimensão objetiva dos direitos fundamentais; na sequência, averiguar-se-ão os fundamentos utilizados pelo Supremo Tribunal Federal na ADPF 457/GO, bem como analisar-se-á a existência ou não de um descompasso entre os fundamentos da decisão do STF e o texto do Projeto de Lei, a partir de uma perspectiva de diálogo institucional. Concluiu-se, através da análise realizada, que há uma divergência no posicionamento adotado pelos dois Poderes, sendo que a mais alta Corte brasileira entende que tais temas podem ser trabalhados na formação pedagógica dos alunos, enquanto que o Projeto de Lei vai no sentido de vedação da alusão a essas temáticas no ambiente escolar.

\footnotetext{
${ }^{1}$ Este artigo foi realizado com apoio da Coordenação de Aperfeiçoamento de Pessoal de Nível Superior - Brasil (CAPES) Código de Financiamento 001, e é resultante das atividades do projeto de pesquisa "“Fórmulas" de aferição da "margem de apreciação do legislador" (Beurteiligungsspielraum des Gesetzgebers) na conformação de políticas públicas de inclusão social e de proteção de minorias pelo Supremo Tribunal Federal e pela Corte Interamericana de Direitos Humanos", financiado pelo CNPq (Edital Universal - Edital 14/2014 - Processo 454740/2014-0) e pela FAPERGS (Programa Pesquisador Gaúcho - Edital 02/2014 - Processo 2351-2551/14-5). A pesquisa é vinculada ao Grupo de Pesquisa "Jurisdição Constitucional aberta" (CNPq) e desenvolvida junto ao Centro Integrado de Estudos e Pesquisas em Políticas Públicas CIEPPP (financiado pelo FINEP) e ao Observatório da Jurisdição Constitucional Latino-Americana (financiado pelo FINEP), ligados ao Programa de Pós-Graduação em Direito - Mestrado e Doutorado da Universidade de Santa Cruz do Sul - UNISC.
} 
LEAL, Mônia Clarissa Henning; VARGAS, Eliziane Fardin de. A questão da ideologia de gênero nas escolas brasileiras: o (des)compasso entre os fundamentos elencados na ADPF 457/GO e no Projeto de

Palavras-chave: ADPF 457/GO; educação de gênero em escolas; Projeto de Lei 246/2019; Supremo Tribunal Federal; proteção de minorias e de grupos vulneráveis.

Abstract: This article intends, through the deductive method, to answer the following question: is there a (dis)alignment between the content in the Bill 246/2019 and the foundations used by the Federal Supreme Court in the decision of the ADPF 457/GO? For that purpose, it will be analyzed, in the first moment, the importance of gender and sexual diversity approach in the school environment for the protection of sexual and gender minorities, under the perspective of the state duties of protection (Schutzpflicht) resulting from the objective dimension of the fundamental rights; next, the foundations used by the Federal Supreme Court in the ADPF 457/GO will be evaluated, as well as the existence or non-existence of a difference between the foundations of the Federal Supreme Court and the text of the Bill, through a perspective of institutional dialogue. It was concluded, through the analysis, that there is a difference in the position adopted by the two Powers, because the highest Brazilian Court understands such themes may be developed in the student's pedagogical formation, while the Bill moves in the direction of sealing references to these themes in the school environment.

Key-words: ADPF 457/GO; gender education in schools; Bill 246/2019; Brazilian Federal Supreme Court; protection of vulnerable and minority groups.

\section{Para citar este artigo}

ABNT NBR 6023:2018

LEAL, Mônia Clarissa Henning; VARGAS, Eliziane Fardin de. A questão da ideologia de gênero nas escolas brasileiras: o (des)compasso entre os fundamentos elencados na ADPF 457/GO e no Projeto de Lei 246/2019. Prisma Jurídico, São Paulo, v. 20, n. 2, p. 216-237, jul./dez. 2021. http://doi.org/10.5585/prismaj.v20n2.18070.

\section{Introdução}

Diante da edição de leis provenientes dos poderes legislativos municipais brasileiros que vedavam a abordagem de temáticas atinentes a gênero, diversidade sexual e identidade de gênero - ou "ideologia de gênero", como disposto em algumas dessas normas - nas escolas, foi questionada a sua constitucionalidade, uma vez que, ao vedarem que essas matérias integrassem os debates escolares, estariam ferindo o direito a uma educação plural, à liberdade de aprender, ensinar e divulgar o pensamento, bem como atingindo frontalmente o pluralismo de ideias e de concepções pedagógicas, fazendo com que a parcela da sociedade integrante desses grupos permaneça "invisível". Diante dessa relevante controvérsia constitucional de interesse nacional, o embate em questão, mais especificamente o caso envolvendo o Município de Novo GamaGO, foi levado ao Supremo Tribunal Federal, para que fosse decidido através da Arguição de Descumprimento de Preceito Fundamental n. 457/GO.

$\mathrm{Na}$ decisão, o Supremo Tribunal Federal considerou inconstitucional a Lei $\mathrm{n}$. 1.516/2015, do Município de Novo Gama, que vedava a utilização de materiais didáticos que 
LEAL, Mônia Clarissa Henning; VARGAS, Eliziane Fardin de. A questão da ideologia de gênero nas escolas brasileiras: o (des)compasso entre os fundamentos elencados na ADPF 457/GO e no Projeto de

possuíssem referência à ideologia de gênero. Porém, de maneira inversa ao decidido pela Corte, atualmente tramita, na Câmara de Deputados, o Projeto de Lei n. 246/2019, o qual propõe que tais temáticas não sejam tratadas nesse meio. ${ }^{2}$ Diante do exposto, empregando-se o método de abordagem dedutivo, pretende-se responder ao seguinte questionamento: há um (des)compasso ${ }^{3}$ entre os fundamentos empregados pelo Supremo Tribunal Federal na decisão da ADPF 457/GO e o texto do Projeto de Lei n. 246/2019, em tramitação na Câmara de Deputados?

Para isso, inicialmente, será abordada a importância do debate sobre gênero e diversidade sexual no ambiente escolar para a proteção das minorias sexuais e de gênero através da educação, como manifestação do dever de proteção estatal (Schutzpflicht) decorrente da dimensão objetiva dos direitos fundamentais; posteriormente, serão analisados os fundamentos empregados na decisão da ADPF 457/GO, oportunidade na qual o Supremo Tribunal Federal decidiu pela inconstitucionalidade da lei questionada, para, ao final, analisar-se a existência ou não de um descompasso entre os fundamentos utilizados pelo mais tribunal brasileiro na ADPF 457/GO e o texto do referido projeto de lei.

\section{0 debate sobre "ideologia de gênero" nas escolas e a proteção das minorias sexuais e de gênero através da educação}

Em que pese a discussão sobre gênero, identidade de gênero e sexualidade no âmbito escolar englobar os direitos à igualdade e de não discriminação das minorias sexuais e de gênero, é essencial iniciar o debate trazendo o contexto histórico do surgimento da exponencial preocupação com a proteção dos direitos humanos e da democracia, visto serem esses direitos os principais conformadores da dignidade humana. Esses institutos, afloraram com maior intensidade no contexto pós Segunda Guerra Mundial, face às atrocidades ocorridas sob a égide dos regimes totalitários vigentes naquele período, razão pela qual a democracia e a proteção aos direitos humanos e fundamentais passaram a ter lugar de destaque na ordem jurídico-

\footnotetext{
${ }^{2} \mathrm{O}$ efeito vinculante (eficácia erga omnes) das decisões do Supremo Tribunal Federal em sede de controle concentrado de constitucionalidade vincula todos os órgãos dos Poderes Executivo e Judiciário, mas não o Poder Legislativo, daí a "última palavra" do STF ser sempre "provisória". Essa não vinculação proporciona ao Legislador o exercício dinâmico de sua atividade interpretativa e a possibilidade de contínua adequação e mutação constitucional "não sendo possível, portanto, limitar o processo legislativo em virtude dos efeitos vinculantes derivados do controle concentrado de constitucionalidade, de maneira a impedir a tramitação e votação de projeto de lei contrário ao entendimento do STF em determinada matéria." (MORAES, 2016, p. 800-801)

${ }^{3}$ Esse descompasso pode ser igualmente visto como um efeito "backlash", já que a propositura do Projeto de Lei n. 246/2019 em sentido inverso ao preconizado na decisão do Supremo Tribunal Federal consubstancia uma reação de desaprovação intensa de uma decisão judicial, desaprovação essa que vem munida de medidas de forte resistência ao teor da decisão e que busca afastar a sua força jurídica. Nesse sentido, Sunstein (2007, p. 435) define "public backlash,", no contexto do direito constitucional, como sendo: "Intense and sustained public disapproval of a judicial ruling, accompanied by aggressive steps to resist that ruling and to remove its legal force.".
} 
LEAL, Mônia Clarissa Henning; VARGAS, Eliziane Fardin de. A questão da ideologia de gênero nas escolas brasileiras: o (des)compasso entre os fundamentos elencados na ADPF 457/GO e no Projeto de

Lei 246/2019

constitucional, sendo considerados elementos fundamentais para a consolidação da dignidade humana e fazendo com que as Constituições superem o critério de proteção das maiorias e passem a dar atenção especial aos grupos minoritários (LEAL, 2007).

No caso da Constituição brasileira de 1988 não foi diferente, especialmente considerando-se o processo de redemocratização do país, evidenciando-se essa elevada preocupação com o resguardo dos direitos fundamentais logo em seus primeiros artigos. Já no artigo $1^{\circ}$, inciso III, da CF é elencado o princípio da dignidade da pessoa humana, seguido pelo princípio da não discriminação, previsto no artigo $3^{\circ}$, inciso IV, da CF, o qual elenca como objetivos fundamentais da República Federativa do Brasil a promoção do bem-estar de todos, "sem preconceitos de origem, raça, sexo, cor, idade e quaisquer outras formas de discriminação"; no mesmo sentido prevê o caput do artigo $5^{\circ}$ da CF que "todos são iguais perante a lei, sem distinção de qualquer natureza" (BRASIL, 1988).

Ressalta-se que a Carta Magna brasileira promove não só a igualdade formal entre os indivíduos como também a igualdade material, reconhecendo e respeitando as diferenças existentes entre as pessoas, sendo que a Constituição de 1988 é considerada a "primeira de nossas constituições a contemplar alguma abertura para o multiculturalismo, ao incumbir-se da proteção das diferentes identidades culturais e étnicas que compõem a Nação brasileira" (SOUZA NETO; SARMENTO, 2016, p. 173).

Considerando-se que para atingir a igualdade material se pressupõe uma atividade prestativa por parte do Estado, capaz de propiciar sua concreta implementação, utilizando da doutrina de Sarlet (2010), é importante ressaltar que:

O certo é que os direitos fundamentais sociais a prestações, diversamente dos direitos
de defesa, objetivam assegurar, mediante a compensação das desigualdades sociais, o
exercício de uma liberdade e igualdade real e efetiva, que pressupõem um
comportamento ativo do Estado, já que a igualdade material não se oferece
simplesmente por si mesma, devendo ser devidamente implementada. Ademais, os
direitos fundamentais sociais almejam uma igualdade real para todos, atingível apenas
por intermédio de uma eliminação das desigualdades, e não por meio de uma
igualdade sem liberdade, podendo afirmar-se, neste contexto, que, em certa medida,
a liberdade e a igualdade são efetivadas por meio dos direitos fundamentais sociais.
(SARLET, 2010, p. 199).

Tanto a igualdade quanto a educação são direitos fundamentais de todos e sua promoção e proteção são deveres do Estado, incumbindo-o da responsabilidade de propiciar meios capazes de efetivar o exercício desses direitos pelos indivíduos. Esse "dever de proteção estatal" (Schutzpflicht) - que compreende ações advindas tanto do Estado quanto de particulares decorre da dimensão objetiva dos direitos fundamentais, a qual abarca a ideia de que os direitos 
LEAL, Mônia Clarissa Henning; VARGAS, Eliziane Fardin de. A questão da ideologia de gênero nas escolas brasileiras: o (des)compasso entre os fundamentos elencados na ADPF 457/GO e no Projeto de

Lei 246/2019

fundamentais desenvolvem bases principiológicas que norteiam e vinculam todos os Poderes e todo o Direito (LEAL, 2007).

Diante da previsão do direito contida nos artigos $6^{\circ}, 205,206$ e 214 da Constituição Federal, com base no dever de proteção estatal decorrente da dimensão objetiva dos direitos fundamentais, comprometeu-se o Estado brasileiro a fornecer uma educação com escopo de gerar o "pleno desenvolvimento da pessoa, seu preparo para o exercício da cidadania e sua qualificação para o trabalho" (BRASIL, 1988). Além disso, deve observar os princípios elencados no artigo 206, incisos I e II, da Constituição Federal, o qual prevê que a prestação do direito à educação ocorrerá com a estrita observância e respeito à "II- liberdade de aprender, ensinar, pesquisar e divulgar o pensamento, a arte e o saber; III- pluralismo de idéias e de concepções pedagógicas, e coexistência de instituições públicas e privadas de ensino" (BRASIL, 1988).

Deste modo, o debate quanto a questões de gênero, sexualidade, empoderamento feminino e igualdade entre homens e mulheres, a educação - através do aporte escolar - é uma grande ferramenta condutora de conhecimento, sendo capaz de conscientizar sobre as diferenças e evitar eventuais condutas preconceituosas e prejudiciais às pessoas integrantes desses grupos, almejando sua integração na sociedade. Nesse sentido, preconiza Pereira, Normanton, Stempliuk (2018, p. 14) que:

\begin{abstract}
A democracia brasileira depende de uma educação que crie as bases da sociedade democrática, que respeite a diversidade e reproduza os princípios e valores constitucionais para que assim, tais valores e princípios sejam reproduzidos nas práticas sociais. Para isso a Constituição Federal adota, de forma expressa, uma concepção de educação que prepare os e as estudantes para o exercício da cidadania, que respeite a diversidade e que assim seja capaz de viver em uma sociedade plural com as mais diversas expressões religiosas, políticas, culturais, étnicas, de sexualidade ou de gênero.
\end{abstract}

No entanto, tal compreensão não impede a criação de leis ${ }^{4}$ com o intuito de vedar o ensino da denominada "ideologia de gênero" em escolas. O impedimento dessa abordagem em âmbito escolar, por meio de legislações municipais, por vezes, decorre da omissão existente no Plano Nacional de Educação, visto que, por ocasião de sua redação e atualização para o decênio

\footnotetext{
${ }^{4}$ Pode ser citada a título de exemplo não só a Lei n. 1.516/2015 do Município de Novo Gama/GO - debatida pelo Supremo Tribunal Federal na decisão da ADPF N. 457/GO - como também outras leis municipais que aguardam o julgamento pelo Supremo Tribunal Federal, como é o caso dos Municípios de Londrina (ADPF n. 600/PR), Foz do Iguaçu (ADPF n. 526/PR), Ipatinga (ADPF 467/MG), Município de Blumenau (ADPF 462/SC) entre outros.

5 O termo "ideologia de gênero" é utilizado por pessoas que apoiam posições de família e costumes tradicionais e defendem que a "ideologia de gênero" é sinônimo da desconstrução dos papéis tradicionais de gênero. (REIS; EGGERT, 2017)
} 
LEAL, Mônia Clarissa Henning; VARGAS, Eliziane Fardin de. A questão da ideologia de gênero nas escolas brasileiras: o (des)compasso entre os fundamentos elencados na ADPF 457/GO e no Projeto de

2014-2024, o Projeto de Lei da Câmara de Deputados n. 103/2012 foi alterado pelo Senado Federal.

A modificação realizada ocorreu no trecho da redação original, a qual previa que "São diretrizes do PNE: [...] III - a superação das desigualdades educacionais, com ênfase na promoção da igualdade racial, regional, de gênero e de orientação sexual e na erradicação de todas as formas de discriminação" (BRASIL, CÂMARA DOS DEPUTADOS, 2012, grifouse). O referido trecho foi suprimido, dando espaço à redação "São diretrizes do PNE: [...] III superação das desigualdades educacionais, com ênfase na promoção da cidadania e na erradicação de todas as formas de discriminação" (BRASIL, SENADO FEDERAL, 2013). Dessa forma, o Plano Nacional de Educação atual (Lei n. 13.005/2014), sancionado em 25 de junho de 2014, passou a referir-se apenas de forma genérica à discriminação, inexistindo qualquer previsão específica sobre a superação de desigualdades de gênero e de orientação sexual.

Na visão de Hernandes (2020, p. 57), sem o debate dessas questões na escola, "colocaremos cidadãos despreparados dentro de uma sociedade nova e transformada, na qual, estes não se adequarão e as consequências podem ser danosas a todos, principalmente à população LGBTI", sendo que, com a inclusão dessas temáticas nos planos educacionais, se estaria desenvolvendo nos indivíduos o ideal de respeito e reconhecimento das diferenças entre as pessoas, prevenindo o acometimento de eventuais condutas preconceituosas. É possível constatar que o próprio Plano Nacional de Educação desestimula, silencia e oculta a possibilidade do debate sobre gênero, identidade de gênero e sexualidade no meio escolar, e mesmo que a temática não tenha a sua abordagem expressamente vedada, essa omissão acaba ocasionando uma invisibilidade do assunto no meio educacional (HERNANDES, 2020).

Essa "invisibilidade" das minorias sexuais é alarmante se forem levados em conta os dados constantes no Boletim n. 03/2020, da Associação Nacional de Travestis e Transexuais (ANTRA), que aponta um total de 89 pessoas transexuais assassinadas apenas no primeiro semestre do ano de 2020, representando um acréscimo de 39\% em relação ao mesmo período do ano de 2019. O mesmo documento ainda salientou que os índices de assassinato de pessoas transexuais vêm aumentando diante da inércia estatal, tendo em vista que o Brasil ainda "não implementou nenhuma medida de proteção junto a população LGBTI+, mesmo depois da decisão do Supremo Tribunal Federal que reconheceu a LGBTIfobia como uma forma do crime de racismo" (ANTRA, 2020).

Do mesmo modo, em relação às minorias de gênero, os dados referentes à prática de feminicídios no Brasil parecem crescer exponencialmente, mesmo após a edição da Lei n. 
LEAL, Mônia Clarissa Henning; VARGAS, Eliziane Fardin de. A questão da ideologia de gênero nas escolas brasileiras: o (des)compasso entre os fundamentos elencados na ADPF 457/GO e no Projeto de

13.104/2015, conhecida popularmente como "Lei do Feminicídio". O Anuário Brasileiro de Segurança Pública aponta que, no ano de 2019, constatou-se um aumento de 11,3\% nos índices desse tipo de crime no país, vitimando 1.206 mulheres que perderam suas vidas em razão da violência de gênero (FÓRUM BRASILEIRO DE SEGURANÇA PÚBLICA, 2019).

Diante da pluralidade e heterogeneidade que caracterizam a sociedade atual, bem como do exponencial crescimento dos índices de violência contra as minorias sexuais e de gênero, Estefam (2016, p. 147) destaca a importância das ações pedagógicas para a proteção da diversidade sexual e combate à homofobia, defendendo a fundamentalidade da "existência de campanhas de educação pública propugnando a igualdade entre pessoas de todas as preferências e opções sexuais", bem como que essas ações devem ocorrer, inclusive, no meio escolar, pois desde a mais tenra idade "é preciso fazer compreender que os seres humanos merecem idêntico respeito, independentemente da orientação sexual".

Importante ressaltar que não se trata apenas de uma educação a fim de prevenir preconceitos, mas também de uma educação inclusiva, já que os indivíduos que compõem esses grupos acabam, muitas vezes, precocemente abandonando o ambiente escolar em razão do preconceito e das violências que sofrem, sendo insustentável sua permanência nos locais de ensino, fazendo com que a situação de vulnerabilidade se agrave de forma exponencial. Dados comprovam que em média $75 \%$ das pessoas transexuais abandonam os estudos e a escola “devido ao preconceito, tanto de colegas de sala como de professores e funcionários da escola. Esse motivo, juntamente com a invisibilidade das pessoas transexuais e a exclusão familiar, as leva à marginalização, dificultando seu acesso ao mercado de trabalho" (PEREIRA; NORMANTON; STEMPLIUK, 2018, p. 16).

Hernandes (2020, p. 58) argumenta que a abordagem dessas temáticas nas salas de aula “tornar-se-ia um instrumento de prevenção ao bullying (intimidação sistêmica), da violência física, do preconceito, da intolerância ao diferente. Professores são cerceados neste tema, reféns de uma direção educacional pressionada pelos próprios pais dos alunos”. Desse modo, a própria liberdade de ensinar e o pluralismo de ideias e concepções pedagógicas do profissional da educação - direitos esses resguardados no artigo 206, incisos II e III, da Constituição Federal são inobservados quando ocorre a omissão referente a esses temas no Plano Nacional de Educação ou quando ocorre uma vedação municipal quanto à possibilidade de abordagem dessas questões, pelos professores, em sala de aula.

Destaca-se que é por meio das práticas pedagógicas que se pode alterar essa realidade desigual e violenta: "a escola pode ser, portanto, espaço de construção de uma sociedade plural, 
LEAL, Mônia Clarissa Henning; VARGAS, Eliziane Fardin de. A questão da ideologia de gênero nas escolas brasileiras: o (des)compasso entre os fundamentos elencados na ADPF 457/GO e no Projeto de

democrática e com respeito, sendo a abordagem de gênero e sexualidade no ensino fundamental para tanto" (PEREIRA; NORMANTON; STEMPLIUK, 2018, p. 16).

Tanto a vedação por parte de leis municipais quanto a omissão do Plano Nacional de Educação contribuem para o silenciamento das questões envolvendo essa parcela da sociedade, o que afronta o direito elencado nos artigos 205 e 206, inciso I, da Constituição Federal, já que impossibilitam uma educação capaz de fornecer o "pleno desenvolvimento da pessoa, seu preparo para o exercício da cidadania e sua qualificação para o trabalho”, desrespeitando, igualmente, o direito à "igualdade de condições para o acesso e permanência na escola" dos indivíduos integrantes dos supramencionados grupos minoritários (BRASIL, 1988).

Assim, tem-se que as proibições do ensino dessas temáticas por meio de legislações municipais violam frontalmente o disposto no artigo 206, inciso II e III, da Constituição Federal, ao mesmo tempo em que a liberdade de aprender e de ensinar, bem como o pluralismo de ideias e concepções pedagógicas dos profissionais da educação, são restringidos de forma excessiva. Mesmo que os professores estivessem atentos ao seu compromisso de formar cidadãos conscientes das diversidades que compõem a sociedade, para, através da educação, promover um meio social menos violento e desigual, sua liberdade de propagar o conhecimento via-se restringida pelas vedações municipais.

Diante da reiterada constatação de leis municipais no Brasil vedando o ensino das temáticas atinentes a gênero, identidade de gênero e diversidade sexual nas escolas, o tópico seguinte é especialmente destinado à análise dos fundamentos utilizados pelo Supremo Tribunal Federal por ocasião do julgamento da ADPF n. 457/GO, na qual se debateu, mais precisamente, sobre a constitucionalidade da Lei n. 1.516/2015 do Município de Novo Gama, que vedava a abordagem dessas questões na rede municipal de ensino.

\section{Arguição de Descumprimento de Preceito Fundamental 457/GO: o posicionamento do Supremo Tribunal Federal acerca da discussão sobre o ensino de ideologia de gênero nas escolas brasileiras}

O Supremo Tribunal Federal julgou, em 27 de abril de 2020, a ADPF 457/GO, declarando a inconstitucionalidade da Lei n. 1.516/2015, advinda de Novo Gama (Goiás). A mencionada legislação vedava que as escolas do Município divulgassem ou fizessem uso de materiais didáticos que possuíssem referência à ideologia de gênero. A ação contou com a relatoria do Ministro Alexandre de Moraes e teve seus pedidos atendidos, por unanimidade, pelos integrantes do Plenário do Supremo Tribunal Federal, nos termos do voto do Relator. 
LEAL, Mônia Clarissa Henning; VARGAS, Eliziane Fardlin de. A questão da ideologia de gênero nas escolas brasileiras: o (des)compasso entre os fundamentos elencados na ADPF 457/GO e no Projeto de

Dentre as violações alegadas pelo Procurador-Geral da República, consta que a norma transgrediria os direitos à igualdade (artigo $5^{\circ}$, caput, da CF), vedação à censura em atividades culturais (artigo $5^{\circ}$, inciso IX, da CF), o devido processo legal substantivo (artigo $5^{\circ}$, inciso LIV, da CF), o Estado laico (artigo 19, inciso I, da CF), a competência privativa da União para legislar sobre diretrizes e bases da educação nacional (artigo 22, inciso XXIV, da CF), o pluralismo de ideias e de concepções pedagógicas (artigo 206, inciso III, da CF) e o direito à liberdade de aprender, ensinar, pesquisar e divulgar o pensamento, a arte e o saber (artigo 206, inciso II, da CF).

Inicialmente, foi debatida a (in)constitucionalidade formal da norma, afirmando o Ministro Alexandre de Moraes existir, na Constituição Federal, a previsão de competência privativa da União para edição de legislação que verse sobre diretrizes e bases para a educação nacional, autorização essa que gerou a edição da Lei de Diretrizes e Bases da Educação Nacional (Lei n. 9.394/1996). Ainda evidenciou a previsão constitucional de competência concorrente da União, Estados e do Distrito Federal para editar legislação sobre educação e ensino, cabendo à União a fixação de normas gerais, sendo autorizada aos Estados apenas competência de cunho suplementar (artigo 24, inciso IX da CF). Diante disso, reconheceu o Ministro Relator a inconstitucionalidade formal da Lei Municipal, em razão da usurpação de competência da União (BRASIL, STF, 2020, p. 32-53).

Nessa senda, o Ministro Gilmar Mendes (BRASIL, STF, 2020, p. 7) asseverou que a lei do Município de Novo Gama consubstancia violação da competência privativa da União, disposta no artigo 22, inciso XXIV da Constituição Federal, bem como atenta contra os “princípios e objetivos fundamentais da República Federativa do Brasil relativos ao pluralismo político e da construção de uma sociedade livre, justa e solidária, sem quaisquer preconceitos artigo $1^{\circ}$, inciso V, e artigo $3^{\circ}$, incisos I e IV, da CF/88". Complementarmente, reconheceu que a lei em comento ostenta vício de constitucionalidade material por afrontar os ditames da Constituição Federal concretizados a partir do artigo $3^{\circ}$ da Lei de Diretrizes e Bases da Educação, os quais afirmam que:

Art. $3^{\circ} \mathrm{O}$ ensino será ministrado com base nos seguintes princípios:

I - igualdade de condições para o acesso e permanência na escola;

II - liberdade de aprender, ensinar, pesquisar e divulgar a cultura, o pensamento, a arte e o saber;

III - pluralismo de idéias (sic.) e de concepções pedagógicas; (BRASIL, 1996) 
LEAL, Mônia Clarissa Henning; VARGAS, Eliziane Fardin de. A questão da ideologia de gênero nas escolas brasileiras: o (des)compasso entre os fundamentos elencados na ADPF 457/GO e no Projeto de

Lei 246/2019

Tem-se, pois, que tanto aos preceitos elencados na Lei de Diretrizes e Bases da Educação quanto aos direitos previstos na Constituição Federal restam atingidos pelo teor dos seguintes trechos da lei municipal de Novo Gama:

Art. $1^{\circ}$. Fica proibida a divulgação de material com referência a ideologia de gênero nas escolas municipais de Novo Gama-GO.

Art. $2^{\circ}$. Todos os materiais didáticos deverão ser analisados antes de serem distribuídos nas escolas municipais de Novo Gama-GO.

Art. $3^{\circ}$. Não poderão fazer parte do material didático nas escolas em Novo Gama-GO materiais que fazem menção ou influenciem ao aluno sobre a ideologia de gênero.

Art. $4^{\circ}$. Materiais que forem recebidos mesmo que por doação com referência a ideologia de gênero deverão ser substituídos por materiais sem referência a mesma. (NOVO GAMA, 2015, www.novogama.go.gov.br)

O voto do Ministro Alexandre de Moraes ainda ressaltou a inconstitucionalidade material da norma local no sentido de que os artigos anteriormente citados afrontariam os princípios constitucionais do artigo 206, incisos II e III, da Constituição Federal, os quais elencam os princípios constitucionais da liberdade de aprender, ensinar, pesquisar e divulgar o pensamento, a arte e o saber, o pluralismo de ideias e de concepções pedagógicas, bem como, consequentemente, feririam a vedação à censura e a liberdade de expressão protegidas pelo artigo $5^{\circ}$, inciso IX, da Constituição Federal (BRASIL, STF, 2020, p. 49).

O Relator afirmou ser o respeito à liberdade de expressão a tônica do pluralismo, já que “a democracia não existirá e a livre participação política não florescerá onde a liberdade de expressão for ceifada, pois esta constitui condição essencial ao pluralismo de ideias, que por sua vez é um valor estruturante para o salutar funcionamento do sistema democrático" (BRASIL, STF, 2020, p. 12). Dessa maneira, considerou que a norma municipal em questão “adere à imposição do silêncio, da censura e, de modo mais abrangente, do obscurantismo como estratégias discursivas dominantes, de modo a enfraquecer ainda mais a fronteira entre heteronormatividade e homofobia" (BRASIL, STF, 2020, p. 13), contribuindo de maneira latente para a perpetuação do preconceito e da desigualdade, cerceando que um importante mecanismo - como é o caso da educação por meio das escolas - possa contribuir para a superação desses estigmas sociais que afetam as minorias sexuais e de gênero.

O Ministro Gilmar Mendes acrescentou, ainda, que, tanto na ordem jurídica nacional como internacional, ${ }^{6}$ há mandamentos que vedam a discriminação e promovem o direito à igualdade. Exemplificou que, no âmbito interno, pode-se mencionar a dignidade da pessoa

\footnotetext{
${ }^{6}$ Segundo Bahia e Bomfim (2018, p. 48), no âmbito do Sistema Interamericano de Proteção aos Direito Humanos, "percebese uma maior preocupação com as demandas LGBTI, sendo que, por exemplo, a CIDH criou uma Relatoria específica para tratar desse tema e vem divulgando relatórios de grande repercussão acerca da violência contra as pessoas LGBTI, e a Corte IDH já vem gerando precedentes sobre direitos desta minoria."
} 
LEAL, Mônia Clarissa Henning; VARGAS, Eliziane Fardlin de. A questão da ideologia de gênero nas escolas brasileiras: o (des)compasso entre os fundamentos elencados na ADPF 457/GO e no Projeto de

humana e o direito à igualdade - respectivamente dispostos nos artigos $1^{\circ}$, inciso III e $5^{\circ}$, caput da Constituição Federal - como manifestações dos direitos individuais que demandam "respeito à autonomia privada e às legítimas opções das pessoas sobre suas escolhas existenciais" (BRASIL, STF, 2020, p. 11). Já na esfera internacional, mencionou a existência dessa proteção em diversos documentos - dos quais o Brasil é signatário - como é o caso da Declaração Universal dos Direitos Humanos (artigos I e II), da Convenção Americana sobre Direitos Humanos (artigo $1^{\circ}$ ), do Pacto Internacional sobre Direitos Civis e Políticos (artigo 26) e dos Princípios de Yogyakarta (Princípios 1 e 2) (BRASIL, STF, 2020, p. 44-45).

A exemplo dessa dupla previsão, rememorou o Ministro Relator que o mais alto tribunal brasileiro já havia se posicionado no sentido de proibir a discriminação em razão do sexo, gênero ou orientação sexual por ocasião do julgamento da ADI n. 4.277, a qual reconheceu o direito de união de casais do mesmo sexo; e que, em igual senda, a Organização das Nações Unidas (ONU) publicou o documento intitulado "Nascidos Livres e Iguais - Orientação sexual e identidade de Gênero no Regime Internacional de Direitos Humanos”, o qual apresenta cinco obrigações dos Estados para proteger os direitos e liberdades fundamentais das pessoas LGBTI+ em razão de suas orientações sexuais e identidades de gênero (BRASIL, STF, 2020, p. 24).

Em consonância com o exposto pelo Ministro Gilmar Mendes, o Ministro Edson Fachin salientou a fundamentalidade do respeito aos ditames internacionais que tratam da matéria, mencionando como documento de referência quanto aos direitos humanos envolvendo identidade de gênero e orientação sexual o exarado pelo Conselho de Direitos Humanos da ONU, chamado de "Princípios de Yogyakarta". Em igual sentido, também se referiu ao posicionamento da Corte Interamericana de Direitos Humanos ${ }^{7}$ sobre o reconhecimento da identidade de gênero como manifestação da liberdade de autodeterminação do ser humano, salientando que o seu reconhecimento deve ser observado como construção identitária livre e autônoma de cada indivíduo (BRASIL, STF, 2020, p. 30-31).

Apesar das menções feitas à Corte Interamericana de Direitos Humanos em relação aos grupos minoritários em questão, os precedentes citados na decisão do Supremo Tribunal Federal, aparentemente, funcionam como simples argumento de reforço à razão da decisão

\footnotetext{
${ }^{7}$ Nesse sentido, reconhecendo o direito à igualdade e não discriminação do indivíduo em razão de sua identidade de gênero e/ou orientação sexual, destacam-se, na jurisprudência da Corte Interamericana de Direitos Humanos, no exercício de sua competência contenciosa, as decisões proferidas nos casos Atala Riffo e crianças vs. Chile (CORTE INTERAMERICANA DE DIREITOS HUMANOS, 2012, www.corteidh.or.cr), no caso Duque vs. Colômbia (CORTE INTERAMERICANA DE DIREITOS HUMANOS, 2016, www.corteidh.or.cr) e Flor Freire vs. Equador (CORTE INTERAMERICANA DE DIREITOS HUMANOS, 2016, www.corteidh.or.cr). Em igual sentido, porém no exercício da sua competência consultiva, a Corte Interamericana de Direitos Humanos emitiu a Opinião Consultiva n ${ }^{\circ}$ 24/2017 (CORTE INTERAMERICANA DE DIREITOS HUMANOS, 2017, www.corteidh.or.cr).
} 
LEAL, Mônia Clarissa Henning; VARGAS, Eliziane Fardin de. A questão da ideologia de gênero nas escolas brasileiras: o (des)compasso entre os fundamentos elencados na ADPF 457/GO e no Projeto de

(obiter dictum), e não como justificativa central da decisão (ratio decidendi), entendendo-se, diante disso, que não houve um efetivo diálogo interjurisdicional, pois, para tanto, seria necessário que se desenvolvesse ainda mais essa articulação entre jurisdições e entre Poderes, "vez que a finalidade perseguida por todos deve ser a melhor concretização de diretos humanos e fundamentais.” (LEAL; MORAES, 2018, p. 515). Desse modo, colocar em prática a teoria dialógica é fundamental para a efetivação ampla dos direitos, "não se configurando a abertura à jurisdição internacional por meio do diálogo como um limitador da soberania estatal, e sim como uma ferramenta de proteção de direitos” (LEAL; MORAES, 2018, p. 515).

O Ministro Edson Fachin ainda afirmou ser constitutiva da dignidade da pessoa humana a devida recognição da identidade de gênero do indivíduo e que "o Estado, para garantir o gozo pleno dos direitos humanos, não pode vedar aos estudantes o acesso ao conhecimento a respeito de seus direitos de personalidade e de identidade" (BRASIL, STF, 2020, p. 4). Do mesmo modo, o Ministro Alexandre de Moraes ressaltou a importância do fixado no Parecer Consultivo OC-24/2017, no qual a Corte IDH, ao interpretar o Pacto de São José da Costa, deixou assentado que:

(i) O reconhecimento da identidade de gênero pelo Estado é de vital importância para garantir o gozo pleno dos direitos humanos das pessoas trans, o que inclui a proteção contra a violência, tortura e maus tratos, o direito à saúde, à educação, ao emprego e à moradia, o acesso à seguridade social, assim como o direito à liberdade de expressão e de associação. (BRASIL, STF, 2020, p. 17)

Diante da constatação de que o direito de autodeterminação do gênero e sexualidade do indivíduo faz parte da dignidade humana, vale ressaltar que "o princípio da dignidade humana envolve tanto limites quanto tarefas para o Estado e a sociedade, cumulando, portanto, as funções defensiva e prestacional" (SARMENTO, 2019, p. 90).

Afirma o Ministro Gilmar Mendes que a existência de normas com esse teor - tanto nacionais quanto internacionais - demonstra a preocupação das ordens jurídicas com a igualdade, sendo que por meio desses dispositivos "permite-se concluir pela existência de um dever estatal de adoção de políticas de combate às desigualdades e à discriminação, inclusive no que se refere aos padrões culturais, sociais e econômicos que produzem essa situação" (BRASIL, STF, 2020, p. 13). Diante do argumento apresentado pelo Ministro, vislumbra-se o reconhecimento, por parte do Supremo Tribunal Federal, de um "dever de proteção estatal" (Schutzpflicht), segundo o qual incumbe ao Estado a obrigação de "zelar, inclusive preventivamente, pela proteção dos direitos fundamentais dos indivíduos não somente contra os poderes públicos, mas também contra agressões provindas de particulares e até mesmo de outros Estados" (SARLET, 2010, p. 148). 
LEAL, Mônia Clarissa Henning; VARGAS, Eliziane Fardin de. A questão da ideologia de gênero nas escolas brasileiras: o (des)compasso entre os fundamentos elencados na ADPF 457/GO e no Projeto de

O Ministro Gilmar Mendes ainda mencionou que a presença do dever de proteção estatal contra a discriminação e desigualdade decorre da dupla percepção dos direitos fundamentais, afirmando que o direito à igualdade e à não discriminação comportam uma esfera subjetiva de direitos concernentes ao indivíduo, bem como abarcam uma dimensão objetiva que fixa uma série de diretrizes que vinculam a atuação do Estado a fim de promover esses direitos. Desse modo, reforçou que a igualdade deve ser compreendida tanto em sua dimensão negativa, no sentido de vedar a discriminação, como sob sua dimensão positiva, proporcionando meios capazes de gerar a integração de grupos estigmatizados e marginalizados. Diante desses fundamentos, o voto foi no sentido de que as referidas normas municipais, "ao proibirem a veiculação de materiais didáticos que contenham discussões sobre questões de gênero e sexualidade, violam as regras gerais e os direitos fundamentais à igualdade e à não discriminação, previstos nas normas internacionais e na Constituição Federal de 1988" (BRASIL, STF, 2020, p. 13-14-15).

Rememora-se que a dimensão objetiva dos direitos fundamentais não apenas gera o dever de proteção estatal, mas também desenvolve uma alteração na relação entre direitos e legislação, gerando a denominada "eficácia de irradiação" (Ausstrahlungswirkung), da qual resulta o entendimento de que toda e qualquer lei infraconstitucional deve observância aos direitos fundamentais, de maneira que "todas as leis devem ser interpretadas e limitadas pelos direitos fundamentais, cujo conteúdo de valor deve ser protegido" (LEAL, 2007, p. 66). Desse modo, a legislação municipal não apenas descumpria o "dever de proteção do Estado" (Schutzpflicht) perante o indivíduo, como desrespeitava a necessária vinculação da ordem infraconstitucional aos preceitos dos direitos fundamentais (Ausstrahlungswirkung).

Diante disso, o reconhecimento da inconstitucionalidade material e formal da Lei $\mathrm{n}$. $1.516 / 2015$ se deu por unanimidade, reconhecendo-se que a norma questionada, ao vedar "a divulgação de material com referência a ideologia de gênero nas escolas municipais, não cumpre com o dever estatal de promover políticas de inclusão e de igualdade, contribuindo para a manutenção da discriminação com base na orientação sexual e identidade de gênero" (BRASIL, STF, 2020, p. 2-3).

Conclusivamente, diante das diversas leis municipais brasileiras vedando que as instituições de ensino tratem sobre assuntos envolvendo questões de gênero, identidade de gênero e diversidade sexual nas escolas - ou "ideologia de gênero", termo mais conhecido popularmente para se referir a essas temáticas - nota-se que o Supremo Tribunal Federal adotou uma postura oposta à dos legislativos municipais, considerada de caráter desigual e discriminatório. 
LEAL, Mônia Clarissa Henning; VARGAS, Eliziane Fardin de. A questão da ideologia de gênero nas escolas brasileiras: o (des)compasso entre os fundamentos elencados na ADPF 457/GO e no Projeto de

A decisão do Supremo na ADPF 457/GO pautou-se no respeito à dignidade humana (artigo $1^{\circ}$, inciso III, CF), à liberdade de aprender e ensinar (artigo 206, inciso II, CF), ao pluralismo de ideias e de concepções pedagógicas (artigo 206, inciso III, CF), bem como resguardou a liberdade de expressão (artigo $5^{\circ}$, inciso IX, CF) e reconheceu o dever do Estado em promover políticas públicas capazes de superar as desigualdades através da educação plural e evitar discriminações que dificultem a permanência dessas minorias nos ambientes de ensino, consolidando o disposto no artigo $3^{\circ}$, incisos I, III e IV, da Constituição Federal.

O teor da decisão do Supremo Tribunal Federal é, claramente, contrário a essas normatizações, porém, o posicionamento adotado não impede, contudo, a propositura de novas iniciativas de lei em sentido contrário, conforme já destacado.

Como exemplo, pode-se mencionar o fato de que atualmente tramita, na Câmara dos Deputados, um projeto de lei ${ }^{8}$ que objetiva instituir o "Programa Escola Sem Partido" na rede brasileira de ensino, o qual prevê expressa vedação à abordagem de questões de gênero no ambiente escolar. Diante do conteúdo do projeto de lei e do atual posicionamento do Supremo Tribunal Federal sobre a inconstitucionalidade da vedação feita por meio de leis municipais, passa-se a tratar, no tópico seguinte, sobre o possível descompasso entre o texto do projeto de lei e os fundamentos empregados no julgamento da ADPF 457/GO.

\section{3 (Des)compasso entre o Poder Legislativo e o Supremo Tribunal Federal}

Como exposto no item anterior, o Supremo Tribunal Federal, no julgamento da ADPF 457/GO, adotou o posicionamento de que as instituições de ensino brasileiras podem abordar assuntos relacionados a gênero, identidade de gênero e sexualidade no ambiente escolar, pelo fato de que essas temáticas integram a dignidade humana e o direito à informação sobre a liberdade de autodeterminação do indivíduo. Defendeu que o Estado, ao vedar que os estudantes tivessem acesso aos materiais didáticos que contenham alusão à ideologia de gênero, estaria deixando de cumprir com seu dever de promoção de políticas públicas inclusivas e de igualdade, de forma a contribuir com a continuidade de discriminações em razão da orientação sexual e da identidade de gênero (BRASIL, STF, 2020, p. 48).

Porém, tanto política quanto socialmente, há uma tendência em omitir assuntos atinentes a gênero e diversidade nas escolas, sendo possível percebê-la, por exemplo, pela ocorrência da supressão das terminologias "gênero" e "orientação sexual" no Plano Nacional

\footnotetext{
${ }^{8}$ Projeto de Lei n. 246/2019, proposto pela deputada Bia Kicis e que atualmente tramita na Câmara de Deputados. (BRASIL, 2019, www.camara.leg.br)
} 
LEAL, Mônia Clarissa Henning; VARGAS, Eliziane Fardin de. A questão da ideologia de gênero nas escolas brasileiras: o (des)compasso entre os fundamentos elencados na ADPF 457/GO e no Projeto de

de Educação 2014-2024, o que, "independente do partido que estiver associado, põe em risco a dignidade humana de pessoas, sustentando a ideia de que identidades dissidentes não são “normais" e que, por isso, devem ser invisíveis ao Estado" (RODRIGUES NETO; NOZU; ROCHA, 2019, p. 90).

É válido rememorar que a supressão dos termos "gênero" e "orientação sexual" na redação do Plano Nacional de Educação 2014-2024 deu margem a interpretações que levaram à edição, por parte de poderes legislativos municipais, de leis antigênero, leis essas que, por mais que tenham sido posteriormente discutidas através de ADPF's e perdido sua eficácia jurídica em razão de sua inconstitucionalidade, impactaram, de certo modo, a sociedade, já que vigoraram "desde o ano de 2015 nos planos municipais de educação. Seus impactos, negativos e graves, contra a liberdade de expressão no campo educacional e com a criminalização das discussões de gênero e sexualidade nas escolas, ainda não podem ser mensurados" (KALIL, 2019, p. 125).

Corroborando com as ideias expressas nas legislações municipais supramencionadas, há um movimento que defende a não abordagem dessas temáticas no âmbito escolar, o intitulado "Programa Escola Sem Partido" ". Esse movimento, em sua origem, buscava impedir uma "doutrinação marxista", mas atualmente volta-se também ao combate da "ideologia de gênero", reivindicando que seja vedado aos profissionais da educação transmitir aos alunos valores opostos daqueles seguidos por seus pais, sendo que "o foco principal é a 'ideologia de gênero', mas a regra contempla também as posições políticas sobre outras questões e mesmo a teoria da evolução das espécies ou o heliocentrismo" (MIGUEL, 2016, p. 601).

Nesse sentido, atualmente, tramita na Câmara dos Deputados o Projeto de Lei n. 246, apresentado em 04 de fevereiro de 2019 pela Deputada Bia Kicis (PSL-DF), o qual objetiva a instituição do "Programa Escola Sem Partido" e justifica a proposta da seguinte maneira:

É fato notório que professores e autores de livros didáticos vêm-se utilizando de suas aulas e de suas obras para tentar obter a adesão dos estudantes a determinadas correntes políticas e ideológicas, bem como para fazer com que eles adotem padrões de julgamento e de conduta moral - especialmente moral sexual incompatíveis com os que lhes são ensinados por seus pais ou responsáveis. (BRASIL. CÂMARA DOS DEPUTADOS, 2019, grifo nosso).

Em aparente concordância com os fundamentos explicitados na decisão da ADPF 457/GO pelo Supremo Tribunal Federal, o artigo $1^{\circ}$ do Projeto Lei prevê que essa atuaria com base nos princípios do "III- pluralismo de ideias e de concepções pedagógicas; IV- liberdade

\footnotetext{
${ }^{9}$ Também chamado de Movimento Escola Sem Partido foi fundado no ano de 2004 pelo advogado Miguel Nagib, mas teve maior visibilidade na década de 2010 quando passou a adentrar mais ativamente no campo do debate sobre questões envolvendo a educação brasileira, defendendo o combate a "ideologia de gênero" nas escolas. (MIGUEL, 2016)
} 
LEAL, Mônia Clarissa Henning; VARGAS, Eliziane Fardin de. A questão da ideologia de gênero nas escolas brasileiras: o (des)compasso entre os fundamentos elencados na ADPF 457/GO e no Projeto de

de aprender, ensinar, pesquisar e divulgar o pensamento, a arte e o saber; V- liberdade de consciência e de crença” (BRASIL. CÂMARA DOS DEPUTADOS, 2019).

Em seguida, prevê que é dever dos professores, no exercício de sua atividade: “Art. $4^{\circ}$ No exercício de suas funções, o professor: I - não se aproveitará da audiência cativa dos alunos para promover os seus próprios interesses, opiniões, concepções ou preferências ideológicas, religiosas, morais, políticas e partidárias"; complementarmente, dispõe o artigo $7^{\circ}$ que ao estudante será concedido o direito de gravar as aulas, com a finalidade de que possa "permitir a melhor absorção do conteúdo ministrado e de viabilizar o pleno exercício do direito dos pais ou responsáveis de ter ciência do processo pedagógico e avaliar a qualidade dos serviços prestados pela escola” (BRASIL. CÂMARA DOS DEPUTADOS, 2019).

Com isso, o movimento "Escola Sem Partido", através do Projeto de Lei, promete uma escola livre de ideologias, onde, da mesma maneira, temáticas afetas a gênero não sejam abordadas em ambiente estudantil, conforme elenca o artigo $2^{\circ}$ do projeto, o qual menciona que “o Poder Público não se imiscuirá no processo de amadurecimento sexual dos alunos, nem permitirá qualquer forma de dogmatismo ou proselitismo na abordagem das questões de gênero" (BRASIL. CÂMARA DOS DEPUTADOS, 2019).

Verifica-se certo viés obscurantista por parte do referido Projeto de Lei - especialmente pelo texto do artigo $2^{\circ}$ - em relação às temáticas de gênero e diversidade sexual, percebendose que “o programa 'Escola Sem Partido' reúne em si o interesse de silenciar as questões de gênero e diversidade sexual e suprimir os conteúdos que, por alguma natureza, ameacem alternância nas relações de poder culturalmente favorecidas" (RODRIGUES NETO; NOZU; ROCHA, 2019, p. 91).

Esse "fechar de olhos" em relação às temáticas de gênero e diversidade sexual na escola aparenta desconsiderar a realidade de educadores que "se veem diariamente desafiados por questões de gênero e sexualidade que eclodem em suas salas de aula, corredores e pátios", situação essa que demonstra a importância da existência da possibilidade de se poder tratar dessas temáticas no meio educacional, já que a pluralidade faz parte tanto da sociedade como do meio escolar. Consequentemente, supor que essas temáticas são introduzidas nas escolas através de "materiais didáticos ou atividades pontuais é demonstrar total desconhecimento do contexto escolar e de seus conflitos, que existem justamente porque a escola - especialmente a escola pública brasileira - é plural e diversa” (MATTOS et al., 2017, p. 94).

Tanto os projetos políticos pedagógicos quanto os materiais de ensino e o trabalho dos profissionais da educação devem propiciar aos alunos uma ampla visão dos conhecimentos técnicos, como também desenvolver o reconhecimento e respeito às diferenças e à igualdade, o 
LEAL, Mônia Clarissa Henning; VARGAS, Eliziane Fardin de. A questão da ideologia de gênero nas escolas brasileiras: o (des)compasso entre os fundamentos elencados na ADPF 457/GO e no Projeto de

que desempenhará um papel decisivo no desenvolvimento de seus comportamentos sociais, de maneira a fornecer maiores possibilidades para que as pessoas façam parte da sociedade "de maneira cooperativa, assimilando seus direitos e deveres para com a ordem pública, reconhecendo a si mesmo e o seu próximo como sujeitos dignos e possibilitando o desenvolvimento pleno de cada pessoa individualmente, a educação constrói cidadania" (RODRIGUES NETO; NOZU; ROCHA, 2019, p. 89).

Evidencia-se, dessa forma, um aparente dissenso entre a proposta do Projeto de Lei n. 246/2019 e os fundamentos levantados pelo Supremo Tribunal Federal na decisão da ADPF 457/GO, que defendeu os princípios da liberdade de aprender e ensinar, bem como o pluralismo de ideias e concepções pedagógicas (artigo 206, incisos II e III, CF), consagrando o direito à liberdade de expressão e à autodeterminação do ser humano, referenciando na ementa da decisão em comento que a atividade exercida pela jurisdição constitucional pauta-se no imprescindível dever de "respeito absoluto à Constituição Federal, havendo, na evolução das Democracias modernas, a imprescindível necessidade de proteger a efetividade dos direitos e garantias fundamentais, em especial das minorias" (BRASIL, STF, 2020, p. 2).

Nesse ponto, importa destacar a questão da "dificuldade contramajoritária" própria da jurisdição constitucional, decorrente do fato de que os juízes, mesmo não sendo legitimados através do voto popular, podem "invalidar as decisões adotadas pelo legislador escolhido pelo povo, invocando, muitas vezes, normas constitucionais de caráter aberto, que são objeto de leituras divergentes na sociedade" (SOUZA NETO; SARMENTO, 2016, p. 35). Souza Neto e Sarmento (2016, p. 38) ainda defendem o entendimento de que "a democracia não equivale à mera prevalência da vontade das maiorias, mas corresponde a um ideal político mais complexo, que também envolve o respeito aos direitos fundamentais e a valores democráticos".

Em relação ao tema, Barroso $(2011,309)$ salienta que:

[...] a Constituição deve desempenhar dois grandes papéis. Um deles é assegurar as regras do jogo democrático, propiciando a participação política ampla e o governo da maioria. Mas a democracia não se resume ao princípio majoritário. Se houver oito católicos e dois muçulmanos em uma sala, não poderá o primeiro grupo deliberar jogar o segundo pela janela, pelo simples fato de estar em maior número. Aí está o segundo grande papel de uma Constituição: proteger valores e direitos fundamentais, mesmo que contra a vontade circunstancial de quem tem mais votos. (BARROSO, 2011, p. 309)

O diálogo interinstitucional, no caso em comento, contribuiria de maneira expressiva para "a agregação de conhecimentos advindos de diferentes fontes e a dificuldade contramajoritária seria atenuada, pois, os outros Poderes e o próprio povo seriam partícipes na construção do significado constitucional" (CLÈVE; LORENZETTO, 2015, p. 197). Desse 
LEAL, Mônia Clarissa Henning; VARGAS, Eliziane Fardin de. A questão da ideologia de gênero nas escolas brasileiras: o (des)compasso entre os fundamentos elencados na ADPF 457/GO e no Projeto de

modo, se todos os âmbitos dos Poderes "estiverem abertos para escutar e aprender com perspectivas diferentes das suas, pode-se esperar que melhores respostas serão formuladas para os problemas referentes ao sentido constitucional em disputa" (CLÈVE; LORENZETTO, 2015, p. 199).

Inclusive, o Supremo Tribunal Federal, ao reconhecer a inconstitucionalidade material da Lei Municipal de Novo Gama, mencionou que a norma, ao vedar o ensino sobre "ideologia de gênero" nas escolas, estaria deixando de executar seu dever estatal de promoção de políticas públicas inclusivas e de fomento à igualdade, fazendo com que se continuasse a perpetuar condutas discriminatórias em razão da orientação sexual e identidade de gênero (BRASIL, STF, 2020, p. 48), indo ao encontro da leitura de Rodrigues Neto, Nozu e Rocha (2019, p. 92) no sentido de que "garantir a formação integral do indivíduo, portanto, deve ser o verdadeiro compromisso Estatal. Fornecer ao indivíduo o acesso à multiplicidade de fontes de informação e de conhecimento deve preponderar independente da corrente política no controle do Estado".

Ressalta-se que, sob a perspectiva do diálogo interinstitucional entre o Poder Legislativo e o Poder Judiciário, aparentemente, este não se efetivou. Segundo Leal e Moraes (2018, p. 511), para que um diálogo entre poderes se perfectibilize, esse pode ocorrer

[...] pela criação de uma lei pelo Legislativo, a sua declaração de inconstitucionalidade pelo Poder Judiciário e, em razão disso, a adoção de um novo posicionamento pelo Poder Legislativo, tanto no sentido de modificar a lei declarada inconstitucional como de reforçar a constitucionalidade daquela lei, de modo a buscar a melhor decisão.

Conclui-se, pois, pelo dissenso entre os fundamentos trazidos pelo Plenário do Supremo Tribunal Federal na ADPF 457/GO e o texto do Projeto de Lei n. 246/2019, visto que sua redação ignora veementemente a existência de uma realidade social brasileira heteronormativa, bem como diverge do Supremo Tribunal Federal em relação ao dever do Estado em promover uma formação plural para o desenvolvimento de cidadãos capazes de respeitar a igualdade e suficientemente conscientes para reconhecer as diversidades existentes entre as pessoas, sejam essas diferenças de gênero, de sexualidade, de identificação de gênero, entre tantas outras possíveis. Tais aspectos apontam, portanto, para um aparente descompasso e desconsideração da importância do diálogo institucional entre os Poderes, não apenas no sentido de atenuação da dificuldade contramajoritária, como também de busca por melhores alternativas para a resolução do embate constitucional quanto ao ensino da temática de gênero e da diversidade sexual no âmbito escolar. 
LEAL, Mônia Clarissa Henning; VARGAS, Eliziane Fardin de. A questão da ideologia de gênero nas escolas brasileiras: o (des)compasso entre os fundamentos elencados na ADPF 457/GO e no Projeto de

\section{Considerações finais}

Inicialmente tratou-se de demonstrar como a escola é um importante vetor de conhecimento sobre as diferenças, capaz de, através da educação inclusiva e plural, propiciar uma profunda mudança no modo de agir do cidadão e, consequentemente, formar uma sociedade menos desigual, fazendo com que a partir da abordagem de temáticas atinentes à "ideologia de gênero", desde logo se conscientize sobre a diversidade e sejam afastadas possíveis condutas discriminatórias, promovendo a proteção de minorias sexuais e de gênero.

Em seguida, tratou-se dos fundamentos empregados pelo Supremo Tribunal Federal na ADPF 457/GO, decisão na qual se decidiu pela inconstitucionalidade da Lei Municipal que impôs a vedação de materiais didáticos que apresentam alusão a temáticas envolvendo ideologia de gênero nas escolas. Demonstrou estar o Poder Judiciário ciente da importância da abordagem dessas temáticas no ambiente escolar, entendendo ser dever do Estado prover políticas públicas inclusivas às minorias, bem como ressaltou a importância da abordagem dessa temáticas no ambiente escolar, devido ao caráter formativo que possui, sendo esse o espaço no qual os indivíduos desenvolvem boa parte de suas condutas sociais futuras e exercitam o reconhecimento das diferenças e o respeito à igualdade. A decisão fundamentou-se na observância dos dispositivos constitucionais atinentes ao princípios da solidariedade e não discriminação (artigo $3^{\circ}$, I e IV/CF), direito à educação (artigo 206, I, II e III/CF) e à liberdade de expressão (artigo $5^{\circ}$, IX/CF), assim como foram mencionados diversos documentos internacionais no mesmo sentido.

Conclusivamente, respondendo ao problema proposto, verificou-se um descompasso entre os fundamentos da decisão do Supremo Tribunal Federal e o Projeto de Lei atualmente em tramitação no Congresso Nacional, por possuírem entre si diversos pontos em desalinhamento, como, por exemplo, o entendimento diverso do elencado pelo STF por parte do texto normativo, que desvia da compreensão de ser dever do Estado a promoção de políticas públicas inclusivas às minorias e por vedar as temáticas atinentes a gênero nas escolas, tema esse de acentuada relevância para que se tenha uma educação inclusiva e plural, capaz de formar cidadãos com consciência e respeito acerca das diferenças dos demais indivíduos.

\section{Referências}

ANTRA. Boletim n. 03/2020 sobre índice de assassinatos de pessoas transexuais no Brasil no $1^{\circ}$ semestre de 2020. Disponível em:

https://antrabrasil.files.wordpress.com/2020/06/boletim-3-2020-assassinatos-antra.pdf.

Acesso em: 13 jul. 2020. 
LEAL, Mônia Clarissa Henning; VARGAS, Eliziane Fardin de. A questão da ideologia de gênero nas escolas brasileiras: o (des)compasso entre os fundamentos elencados na ADPF 457/GO e no Projeto de

BAHIA, Alexandre G. Melo Franco de Moraes; BOMFIM, Rainer. Análise dos precedentes que envolvem discriminação por orientação sexual no Sistema Interamericana de Direitos Humanos. In: DESLANDES, Keila (Coord.). Homotransfobia e direitos sexuais: debates e embates contemporâneos. Belo Horizonte: Autêntica Editora, 2018. p. 31-51.

BARROSO, Luís Roberto. Curso de Direito Constitucional Contemporâneo: os conceitos fundamentais e a construção do novo modelo. 3. ed. São Paulo: Editora Saraiva, 2011.

BRASIL. Câmara dos Deputados. Projeto de Lei n. 103, de 2012. Aprova o Plano Nacional de Educação - PNE e dá outras providências. Brasília, DF, de 2012. Disponível em:

https://www25.senado.leg.br/web/atividade/materias/-/materia/108259. Acesso em: 20 jul. 2020.

BRASIL. Câmara dos Deputados. Projeto de Lei n. 246, de 04 de fevereiro de 2019. Institui o "Programa Escola sem Partido". Disponível em:

https://www.camara.leg.br/proposicoesWeb/fichadetramitacao?idProposicao=2190752. Acesso em: 21 jul. 2020.

BRASIL. Constituição da República Federativa do Brasil (1988). Disponível em: http://www.planalto.gov.br/ccivil_03/constituicao/constituicao.htm. Acesso em: 12 jul. 2020.

BRASIL. Lei n. 9.394, de 20 de dezembro de 1996. Estabelece as diretrizes e bases da educação nacional. Disponível em: http://www.planalto.gov.br/ccivil_03/leis/19394.htm. Acesso em: 10 jul. 2020.

BRASIL. Senado Federal. Parecer n. 1.567, de 2013. Redação final do Substitutivo do Senado ao Projeto de Lei da Câmara n. 103, de 2012 (n. 8.035, de 2010, na Casa de origem). Brasília, DF, 17 dez. 2013. Disponível em: https://www25.senado.leg.br/web/atividade/materias/-/materia/108259. Acesso em: 20 jul. 2020.

BRASIL. Supremo Tribunal Federal (Tribunal Pleno). Arguição de Descumprimento de Preceito Fundamental n. 457/GO. Relator: Min. Alexandre de Moraes, 27 de abril de 2020. Disponível em: http://portal.stf.jus.br/processos/detalhe.asp?incidente=519288. Acesso em: 12 jul. 2020.

CLÈVE, Clèmerson Merlin; LORENZETTO, Bruno Meneses. Diálogos institucionais: estrutura e legitimidade. Revista de Investigações Constitucionais, Curitiba, vol. 2, n. 3, p. 183-206, set./dez. 2015. Disponível em: https://revistas.ufpr.br/rinc/article/view/44534. Acesso em: 27 ago. 2020.

\section{CORTE INTERAMERICANA DE DIREITOS HUMANOS. Opinión Consultiva OC-} 24/2017 de 24 de noviembre de 2017, solicitada por la República de Costa Rica: identidad de género, e igualdad e no discriminación a parejas del mismo sexo. San José da Costa Rica, 2017. Disponível em: https://www.corteidh.or.cr/docs/opiniones/seriea_24_esp.pdf. Acesso em: 29 ago. 2020.

CORTE INTERAMERICANA DE DIREITOS HUMANOS. Caso Atala Riffo e crianças vs. Chile: sentença de 24 de fevereiro de 2012 (mérito, reparações e custas). San José da Costa 
LEAL, Mônia Clarissa Henning; VARGAS, Eliziane Fardin de. A questão da ideologia de gênero nas escolas brasileiras: o (des)compasso entre os fundamentos elencados na ADPF 457/GO e no Projeto de

Rica, 2012. Disponível em:

https://www.corteidh.or.cr/docs/casos/articulos/seriec_239_por.pdf. Acesso em: 29 ago. 2020.

CORTE INTERAMERICANA DE DIREITOS HUMANOS. Caso Flor Freire vs. Ecuador: sentencia de 31 de agosto de 2016 (excepción preliminar, fondo, reparaciones y costas). San José da Costa Rica, 2016. Disponível em:

http://www.corteidh.or.cr/docs/casos/articulos/seriec_315_esp.pdf. Acesso em: 29 ago. 2020.

CORTE INTERAMERICANA DE DIREITOS HUMANOS. Caso Duque vs. Colombia: sentencia de 26 de febrero de 2016 (excepciones preliminares, fondo, reparaciones y costas). San José da Costa Rica, 2016. Disponível em:

http://www.corteidh.or.cr/docs/casos/articulos/seriec_310_esp.pdf. Acesso em: 29 ago. 2020.

ESTEFAM, André. Homossexualidade, prostituição e estupro: um estudo à luz da dignidade humana. São Paulo: Saraiva, 2016.

FÓRUM BRASILEIRO DE SEGURANÇA PÚBLICA. Anuário Brasileiro de Segurança Pública, 26 jun. 2019. Disponível em: https://forumseguranca.org.br/wpcontent/uploads/2019/10/Anuario-2019-FINAL_21.10.19.pdf. Acesso em: 13 jul. 2020.

HERNANDES, Margareth da Silva. O silenciamento sobre as questões de gênero na escola: A inconstitucionalidade de leis e normativas recentes na área da educação. In: BRASIL, Charles dos Santos. O direito à diferença: contribuições para uma análise crítica do Direito. Rio Branco: Edufac, 2020.

KALIL, Isabela Oliveira. Incursões da "ideologia de gênero" na educação. Revista Internacional de Direitos Humanos, v. 16, n. 29, p. 119-128, 2019. Disponível em: https://sur.conectas.org/incursoes-da-ideologia-de-genero-na-educacao/. Acesso em: 20 jul. 2020.

LEAL, Mônia Clarissa Hennig. Jurisdição Constitucional Aberta: Reflexões sobre a legitimidade e os limites da jurisdição constitucional democrática - uma abordagem a partir das teorias constitucionais alemã e norte americana. Rio de Janeiro: Lúmen Júris, 2007.

LEAL, Mônia Clarissa Hennig. MORAES, Maria Valentina de. A margem de apreciação (nacional e do legislador) e o diálogo entre cortes e entre poderes: meios de compreensão dos mecanismos de proteção dos direitos humanos e fundamentais. Anuario de Derecho Constitucional Latinoamericano. Bogotá, 2018. p. 497-518. Disponível em: https://www.corteidh.or.cr/tablas/r39260.pdf. Acesso em: 29 ago. 2020.

MATTOS, Amana et al. Educação e liberdade: apontamentos para um bom combate ao Projeto de Lei Escola sem Partido. In: FRIGOTTO, Gaudêncio (org.). Escola "sem" partido: esfinge que ameaça a educação e a sociedade brasileira. Rio de Janeiro: UERJ, LPP, 2017. p. 87-104.

MIGUEL, Luis Felipe. Da “doutrinação marxista” à" ideologia de gênero"- Escola Sem Partido e as leis da mordaça no parlamento brasileiro. Revista Direito e Práxis, v. 7, n. 15, p. 590-621, 2016. Disponível em: https://www.redalyc.org/pdf/3509/350947688019.pdf. Acesso em: 20 jul. 2020. 
LEAL, Mônia Clarissa Henning; VARGAS, Eliziane Fardin de. A questão da ideologia de gênero nas escolas brasileiras: o (des)compasso entre os fundamentos elencados na ADPF 457/GO e no Projeto de

MORAES, Alexandre de. Direito Constitucional. 32. ed. São Paulo: Atlas, 2016.

NOVO GAMA. Lei 1.516, de 30 de junho de 2015. [Lei declarada inconstitucional conforme decisão DPF n ${ }^{\circ} .457$, do Supremo Tribunal de Federal] proíbe material com informações de ideologia de gênero nas escolas municipais de Novo Gama - GO e dá outras providências. Disponível em:

http://acessoainformacao.novogama.go.gov.br/legislacao/lei/id=49. Acesso em: 20 jul. 2020.

PEREIRA, A. C. A.; NORMANTON, A. C. M.; STEMPLIUK, P. de A. A inconstitucionalidade da proibição da educação sobre gênero. Cadernos da Defensoria do Estado de São Paulo, São Paulo, v. 3, n. 8, p. 8-19, fev. 2018. Disponível em: https://www.defensoria.sp.def.br/cadernos_defensoria/volume8.aspx. Acesos em: 13 jul. 2020.

REIS, Toni; EGGERT, Edla. Ideologia de gênero: uma falácia construída sobre os planos de educação brasileiros. Educação \& Sociedade, Campinas, v. 38, n. 138, p. 9-26, jan. 2017. Disponível em: http://www.scielo.br/scielo.php?script=sci_arttext\&pid=S010173302017000100009\&lng=pt\&nrm=iso. Acesso em: 22 jul. 2020.

RODRIGUES NETO, A.; NOZU, W. C. S.; ROCHA, A. C. S. Direito à educação cidadã: reflexões sobre o programa escola sem partido. Educação em Revista, Marília, v. 20, p. 8398, 2019. Disponível em: file://C:/Users/ADMIN/Downloads/9374-Texto\%20do\%20artigo30519-1-10-20191023\%20(1).pdf. Acesso em: 20 jul. 2020.

SARLET, Ingo Wolfgang. A eficácia dos direitos fundamentais: uma teoria geral dos direitos fundamentais na perspectiva constitucional. 10. ed. Porto Alegre: Livraria do Advogado Editora, 2010.

SARMENTO, Daniel. Dignidade da pessoa humana: conteúdo, trajetórias e metodologia. 2 ed. Belo Horizonte: Fórum, 2019.

SOUZA NETO, Cláudio Pereira de; SARMENTO, Daniel. Direito constitucional: teoria, história e métodos de trabalho. 2. ed. Belo Horizonte: Fórum, 2016.

SUNSTEIN, Cass R. Backlash's Travels. Harvard Civil Rights-Civil Liberties Law

Review, v. 42, p. 435-449, 2007. 